\title{
The effects of housing and preshock on activity-stress ulcer
}

\author{
WILLIAM P. PARÉ and ELO VALDSAAR \\ Veterans Administration Medical Center, Perry Point, Maryland
}

\begin{abstract}
Rats were either group-housed, four rats per cage, or housed singly for 6 weeks. Subgroups were subsequently exposed to a daily 3-min 1.25-mA grid shock for 5 days. The rats were then housed in running-wheel activity cages and, following a 4-day free-feeding period, were fed only $1 \mathrm{~h}$ daily for 20 days. Group-housed rats had more ulcers, but the previously reported protective effect of preshock was not observed in this study.
\end{abstract}

Rats that are housed in groups are subsequently more susceptible to stress-induced ulceration (Ader, 1965, 1971; Stern, Winokur, Eisenstein, Taylor, \& Sly, 1960). This effect has been observed primarily with the ulcerogenic technique of restraint. In comparing singly housed rats with group-housed rats from two different studies, Murison and Isaksen $(1980,1981)$ provided evidence supporting the notion that group housing was a risk factor for stress ulcer. But they also reported data that suggested that prior experience with grid shock reduced the grouphoused rat's subsequent vulnerability to restraint-induced ulceration. The protection provided by the preshock intervention is remarkable, and would be more significant if the effect were demonstrated with other ulcerogenic procedures. Unfortunately, the various ulcerogenic procedures may involve different physiological mechanisms (Paré, Glavin, \& Vincent, 1978; Sines, 1979), thereby reducing the general applicability of the preshock effect. The purpose of the present investigation was to determine if the housing and preshock effects could be demonstrated in rats exposed to the activity-stress (A-S) ulcer procedure. With this procedure, young adult rats are housed in running-wheel activity cages and fed $1 \mathrm{~h}$ daily. These animals run more each day while eating progressively less, and usually within 2 weeks die and reveal stomach ulcers when autopsied (Paré, 1976). In this study, group-housed rats were subjected to daily grid-shock stress and subsequently exposed to the A-S procedure in order to determine if preshock reversed the vulnerability of the grouphoused rats to stress ulcer.

\section{METHOD}

\section{Subjects and Apparatus}

The study used 48 male Long-Evans rats that had been bred and raised in this laboratory. Mean body weight at the beginning of the study was $290.3 \mathrm{~g}$. The shock chambers measured $18 \times 18 \times$ $20.3 \mathrm{~cm}$ and were constructed with clear plastic walls and a grid

The authors' mailing address is: V.A. Medical Center, Perry Point, MD 21902. floor composed of brass rods spaced $1.25 \mathrm{~cm}$ apart. Standard Wahmann (Baltimore, Md.) running-wheel activity cages were used for the activity-stress portion of the study. Each activity wheel was equipped with an adjoining cage measuring $23 \times 15 \times 13 \mathrm{~cm}$. A sliding door separated the cage from its adjoining wheel. Wheel revolutions were recorded by a mechanical digital counter on each cage.

\section{Procedure}

The procedure was organized into three phases; Phase 1 involved a 6-week housing phase, Phase 2 was a 5-day preshock phase, and Phase 3 consisted of the 3-week A-S procedure. In Phase 1, all animals were separated into two groups with equal mean body weights. Rats in the singly housed treatment $(n=24)$ were individually housed in standard single cages measuring $17 \times 19 \times 24 \mathrm{~cm}$. Rats in the group-housed treatment $(n=24)$ were placed, four rats per cage, in six cages measuring $18 \times 24 \times 42 \mathrm{~cm}$. Food and water were always available. Food consisted of Purina Rat Chow pellets placed in wire-mesh wall hoppers in all cages. All animals remained in their respective housing condition for a period of 6 weeks. At the end of each week, all rats were weighed. During Phase 2, the two housing-treatment groups were further subdivided into shock and no-shock groups. This produced four treatment groups $(\mathrm{n}=$ 12), namely group-housed, shock (GH-S), group-housed, no shock (GH-NS), singly housed, shock (SH-S), and singly housed, no shock (SH-NS). All rats were removed from their respective housing conditions and individually placed in the single shock chambers. Rats in the preshock treatments were subjected to the schedule described by Murison and Isaksen (1981). This involved placing the rat in the shock chamber for $3.5 \mathrm{~min}$. During the last $3 \mathrm{~min}$, the rats received $1.25 \mathrm{~mA}$ of scrambled footshock. The rats were subsequently weighed and returned to their colony cages. Rats in the noshock treatments were simply placed in the shock chamber for $3.5 \mathrm{~min}$ but never shocked. This treatment was administered for 5 consecutive days, with Phase 3 starting the next day. During Phase 3, the A-S phase, all rats were individually housed in activitywheel running cages for a 4-day habituation period. During this habituation period, all rats had continuous access to food (granular Purina Rat Chow) and water and also had access to the running wheel. Food was provided in a 100 -cc jar clamped to the inside wall of the cage. On the 5th day, food was withdrawn from all rats at 9 a.m. On the following day, and the next 20 days, the rats were fed for $1 \mathrm{~h}$ between 9 and 10 a.m. Food consumption, body weight, and activity (i.e., number of wheel revolutions) were recorded each day for each rat. Room temperature was controlled at $74^{\circ}-75^{\circ} \mathrm{C}$, and daylight conditions were artificially maintained between 6 a.m. and 6 p.m.

Once the A-S procedure was initiated, some rats became ill. When rats become moribund, they were sacrificed. Phase 3 was termi- 
nated after 20 days of the 1-h feeding schedule. Rats still alive at this time were sacrificed. When the rats were sacrificed, the stomachs were removed and inspected immediately with a dissecting microscope by a technician who was unaware of the rat's grouptreatment condition. The dissecting microscope was equipped with a micrometer disk, whereby ulcer size could be determined. The number and cumulative length of ulcers were recorded.

\section{RESULTS}

During Phase 1, the housing phase, rats grew at different rates. Singly housed rats were heavier at the end of this phase. Analysis of body-weight data for the habituation period of Phase 3 revealed a significant difference for the main effect of housing $[F(1,41)=4.88, p<.03]$. Group-housed rats also lost significantly more weight during the restricted feeding period $[\mathrm{F}(1,41)=5.54, \mathrm{p}<$ $.02]$. These data are illustrated by Figure 1 .

An analysis of the daily running scores, for the first 10 days of 1-h feeding, showed a significant increase in activity once the restricted feeding schedule was initiated $[F(9,378)=14.39, p<.001]$. However, there were no significant differences for the main effects of housing $[F(1,42)=.43]$ or shock $[F(1,42)=.08]$.

During the habituation period of the A-S phase, all rats ate more on consecutive days $[\mathrm{F}(4,108)=11.48, \mathrm{p}<$ $.01]$, but there were no group differences on the basis of housing $[F(1,36)=0.26]$ or shock $[F(1,36)=.06]$. An ANOVA applied to the feeding data for the first 14 days of restricted feeding yielded significant differences for the main effect of days $[F(13,468)=24.63, p<.001]$ and shock $[\mathrm{F}(1,36)=5.08, \mathrm{p}<.05]$. Thus, rats ate more on consecutive days of 1-h feeding, and rats exposed to the preshock treatment ate less than rats in the no-shock condition. Housing conditions were not related to any significant group differences in eating. Figure 2 illustrates these results.

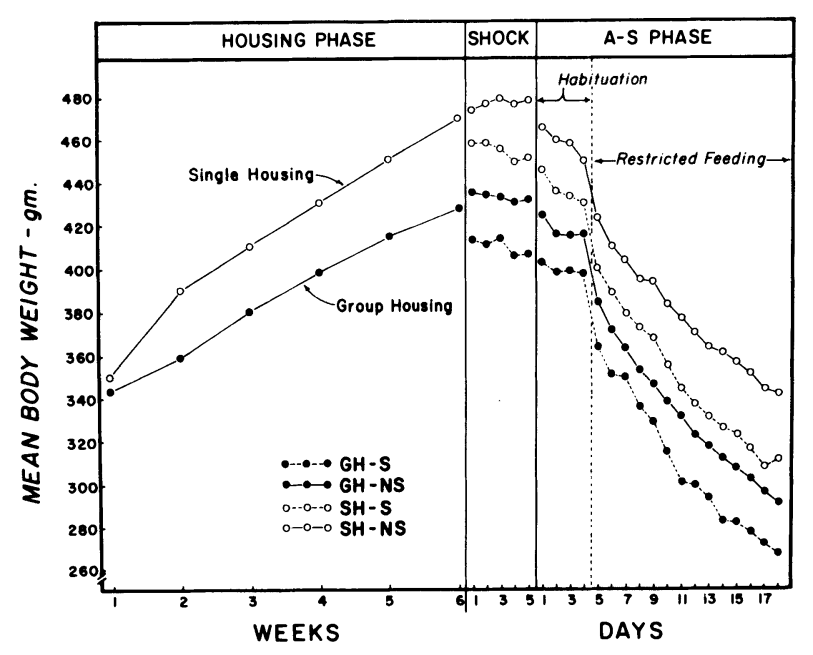

Figure 1. Mean body weight for the four treatment conditions. Body weight was determined weekly during the housing period and daily during the shock and A-S periods.

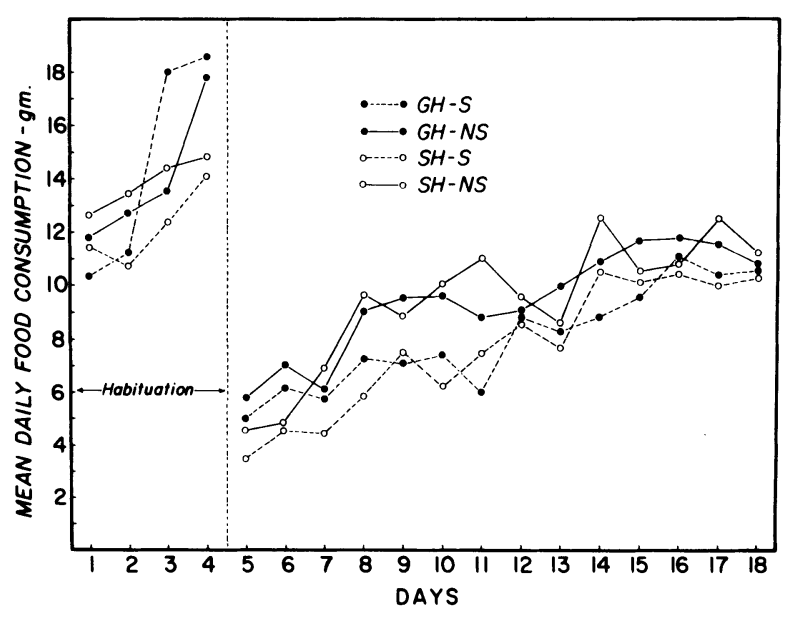

Figure 2. Mean daily food consumption for the 4-day habituation period and the first 14 days of restricted feeding for the activitystress procedure.

More group-housed rats had ulcers than did singly housed rats $\left[\chi^{2}(1, \mathrm{~N}=48)=10.32, \mathrm{p}<.001\right]$. These data are summarized in Table 1. An ANOVA applied to the ulcer data revealed that group-housed rats had more ulcers $[\mathrm{F}(1,44)=8.52, \mathrm{p}<.01]$ and larger ulcers $[F(1,44)=9.14, p<.01]$ than the singly housed animals. The main effect of shock and the interaction of shock and housing did not produce significant differences. Thus, the shock treatment alone did not yield differential group effects. In order to determine the relationship between independent and dependent variables, a stepwise multiple regression (Snedecor \& Cochran, 1967) was conducted between the dependent variable of ulcer size and the independent variables of housing condition, shock condition, mean daily running score, body weight on Day 1 of A-S, and mean daily food consumption during A-S. Cutoff values were established for an $F(1,44)=2.50$ or greater, at $\mathrm{p}<.05$. This analysis revealed that ulcer size was best predicted by the variable of Day 1 body weight, followed by the variable of housing condition. The $\mathrm{r}^{2}$ value for these two variables combined was $0.24[F(2,43)=$ $6.75, \mathrm{p}<.05]$. The other four variables did not contribute significantly in predicting ulcer size in this particular analysis.

\section{DISCUSSION}

Rats exposed only to group-housing, without subsequent stress, do not reveal stomach lesions (Stern et al., 1960). However, exposure to group housing usually increases an animal's susceptibility to stress ulcer when subsequently subjected to an ulcerogenic procedure (Ader, 1965, 1971; Stern et al., 1960). This effect has been observed almost exclusively in rats subjected to restraint stress, but the mechanisms whereby this effect would be demonstrated in the A-S procedure is unknown. The effect of group housing on A-S ulcer, namely the results 
Table 1

Mean ( \pm SE) Survival Days, Number of Ulcers, and Cumulative Length of Ulcers for Rats in the Four Treatment Conditions

\begin{tabular}{lcccr}
\hline \multicolumn{1}{c}{ Treatments } & \multirow{2}{c}{$\begin{array}{c}\text { No. of Rats } \\
\text { with Ulcers* }\end{array}$} & $\begin{array}{c}\text { Survival } \\
\text { Days }\end{array}$ & Number of Ulcers & Length of Ulcers \\
\cline { 4 - 5 } Single-housed (no shock) & 1 & 19.4 & $1.1 \pm 0.5$ & $1.0 \pm 0.1$ \\
Single-housed (shock) & 7 & 16.6 & $14.5 \pm 6.9$ & $26.7 \pm 10.6$ \\
Group-housed (no shock) & 10 & 16.4 & $22.0 \pm 10.2$ & $45.4 \pm 12.5$ \\
Group-housed (shock) & 10 & 13.7 & $27.6 \pm 7.3$ & $62.2 \pm 18.7$ \\
\hline$*_{n}=12$. & & &
\end{tabular}

of the present study, may be partially related to body weight. Smaller rats are more susceptible to A-S ulcer (Paré, 1975). Group-housed rats eat less (Rosen, 1961; Shelley, 1965) and weigh less (Hatch, Wiberg, Zawidzka, Cann, Airth, \& Grice, 1965) than age-matched singly housed rats. In addition, isolates adjust more readily to the subsequent single housing and restricted feeding schedule of the A-S procedure (Paré, Vincent, \& Natelson, 1985). Paré et al.'s (1985) study also indicated that isolates ate more during single housing and carried this consummatory pattern over the A-S procedure, so that isolates ate more during A-S than control rats that had been group-housed prior to A-S. The results were not replicated in the present study, but the inclusion of the preshock treatment makes it difficult to compare the two studies. In the present study, group-housed rats were significantly lighter than singly housed rats at the beginning of Phase 3, the A-S procedure. Thus, they entered the A-S procedure at greater risk for stress ulcer, not necessarily because of their group-housing treatment, but because they were smaller. Therefore, the effects of Phase 1 housing on susceptibility to A-S ulcer may be due not necessarily to group housing per se, but to the fact that this grouphousing condition retards body weight increases and the smaller animal is more susceptible to A-S ulcer. In order to differentiate the relative contributions of housing and initial body weight to stress-ulcer susceptibility, a replication of the present study wherein a singly housed control group would be added with body weights yoked to their group-housed counterparts would be valuable. Any differences in ulcer incidence would then be attributable to the differences in prior housing.

The running-wheel activity data failed to reveal any group differences. This was unexpected, since most A-S studies have usually reported that ulcer incidence and running activity are positively related (Paré, 1976; Paré \& Houser, 1973). In this study, such other factors as body weight and housing were more closely related to ulcer incidence. This may suggest that running activity may have etiological significance when subject and environmental variables are held constant.

The present study did not support the Murison and Isaksen (1981) study with respect to the preshock manipulation. Murison and Isaksen reported that preshock reduced subsequent vulnerability to restraint ulcer. In this study, we reported that preshock did not protect from A-S ulcer. As a matter of fact, the results were in the opposite direction, that is, preshock seemed to have an exacerbating effect by increasing ulcer severity in all rats so treated irrespective of whether they had been isolates or grouphoused during Phase 1. It must be emphasized that the preshock treatment did not produce significant differences in ulcer incidence between treatment groups, but the fact that the group means were in the opposite direction to that reported by Murison and Isaksen (1981) might warrant some discussion and suggestions. Accordingly, it is suggested that preshock may increase ulceration by diminishing the protective effects of food. Food in the stomach is a defensive factor for stress ulcer (Mikhail \& Hirschberg, 1972; Paré, 1972), and grid shock is followed by a reduced food consumption in rats previously shocked (Paré, 1965). The preshock treatment in this study led to a diminished food intake in GH-S and SH-S rats. Thus, group-housed rats, which were already at risk for stress ulcer due to their smaller size, were made more vulnerable by the preshock treatment. The fact that previously group-housed rats lost significantly more weight during the A-S procedure may reflect in part the influence of the preshock treatment.

A comparison of this study with the Murison and Isaksen (1981) study raises a number of interesting points. First, it supports the previous reports regarding the housing variable, although the body-weight consideration in this study might represent a more parsimonious explanation. Second, the discrepancy with respect to the preshock effect emphasizes the notion that the physiological mechanisms for A-S ulcer and restraint ulcer are different. Finally, both this study and other reports (Glavin, 1984; Paré et al., 1985) suggest that developmental and prestress variables may have etiological significance as precipitating factors for stress-ulcer disease.

\section{REFERENCES}

ADER, R. (1965). Effects of early experience and differential housing on behavior and susceptibility to gastric erosions in the rat. Journal of Comparative and Physiological Psychology, 60, 233-238.

ADER, R. (1971). Experimentally induced gastric lesions. Advances in Psychosomatic Medicine, 6, 1-39.

Glavin, G. (1984). Prenatal maternal stress: Differential effects upon male and female offspring responses to stress as adults. Pavlovian Journal of Biological Science, 19, 157-159.

Hatch, A. M., Wiberg, G. S., Zawidzka, Z., Cann, M., Airth, J. M., \& GRICE, H. C. (1965). Isolation syndrome in the rat. Toxicology and Applied Pharmacology, 7, 737-745. 
Mikhail, A. A., \& Hirschberg, J. (1972). Ulceration in the rat's forestomach: Its reduction by non-nutritive bulky substances. Physiology \& Behavior, 8, 769-770.

MURISON, R., \& ISAKSEN, E. (1980). The effects of pre-shock on adrenocortical and somatic responses to subsequent restraint stress. IRCS Medical Science, 8, 888-889.

MURISON, R., \& ISAKSEN, E. (1981). The effects of pre-shock on open field activity and stress-induced gastric ulceration in group housed rats. IRCS Medical Science, 9, 1138.

PARÉ, W. P. (1965). Stress and consummatory behavior in the albino rat. Psychological Reports, 16, 399-405.

PARÉ, W. P. (1972). Conflict duration, feeding schedule, and strain differences in conflict-induced gastric ulcers. Physiology \& Behavior, 8, 165-171.

PARÉ, W. P. (1975). The influence of food consumption and running activity on the activity-stress ulcer in the rat. American Journal of Digestive Diseases, 20, 262-273.

PARÉ, W. P. (1976). The activity-stress ulcer: Frequency and chronicity. Physiology \& Behavior, 16, 699-704.

Paré, W. P., Glavin, G. B., \& Vincent, G. P. (1978). The effects of cimetidine on stress ulceration and secretion in the rat. Biochemistry, Pharmacology and Behavior, 8, 711-715.
PARÉ, W. P., \& Houser, V. P. (1973). Activity and food-restriction effects on gastric glandular lesions in the rat: The activity-stress ulcer. Bulletin of the Psychonomic Society, 2, 213-214.

Paré, W. P., Vincent, G. P., \& Natelson, B. H. (1985). The effects of daily feeding schedule and housing on incidence of activitystress ulcer. Physiology \& Behavior, 34, 423-429.

Rosen, J. (1961). Dominance behavior of the adult rat as a function of early social experience. Journal of Genetic Psychology, 99, 145-151.

SHELley, H. P. (1965). Eating behavior: Social facilitation or social inhibition? Psychonomic Science, 3, 521-522.

Sines, J. O. (1979). Non-pharmacological and non-surgical resistance to stress ulcers in temperamentally and physiologically susceptible rats. Journal of Psychosomatic Research, 23, 77-82.

SNEDecor, G. W., \& CochraN, W. G. (1967). Statistical methods (6th ed.). Ames, Iowa: Iowa State University Press.

Stern, J. A., Winokur, G., Eisenstein, A., Taylor, R., \& Sly, M. (1960). The effect of group vs. individual housing on behaviour and physiological responses to stress in the albino rat. Journal of Psychosomatic Research, 4, 185-190.

(Manuscript received September 3, 1984; revision accepted for publication March 20, 1985.) 